\title{
Oestrogen replacement therapy reduces total plasma homocysteine and enhances genomic DNA methylation in postmenopausal women
}

\author{
Simonetta Friso ${ }^{1}$, Stefania Lamon-Fava ${ }^{2}$, Hyeran $\mathrm{Jang}^{3}$, Ernst J. Schaefer ${ }^{2}$, Roberto Corrocher ${ }^{1}$ \\ and Sang-Woon $\mathrm{Choi}^{3}$ \\ ${ }^{1}$ Department of Clinical and Experimental Medicine, University of Verona School of Medicine, Policlinico 'G.B. Rossi', P.le L.A. \\ Scuro 10, 37134 Verona, Italy \\ ${ }^{2}$ Lipid Metabolism Laboratory, Jean Mayer USDA Human Nutrition Research Center on Aging at Tufts University, Boston, \\ Massachusetts, USA \\ ${ }^{3}$ Vitamins and Carcinogenesis Laboratory, Jean Mayer USDA Human Nutrition Research Center on Aging at Tufts University, \\ Boston, Massachusetts, USA
}

(Received 5 June 2006 - Revised 2 October 2006 - Accepted 30 October 2006)

\begin{abstract}
Although oestrogen replacement therapy (ERT), which can affect the risk of major cancers, has been known to reduce total plasma homocysteine concentrations in postmenopausal women, the mechanisms and subsequent molecular changes have not yet been defined. To investigate the effect of ERT on homocysteine metabolism, thirteen healthy postmenopausal women were enrolled in a double-blind, placebo-controlled, randomized, cross-over study consisting of two 8-week long phases, placebo and conjugated equine oestrogen (CEE; 0.625 mg/d). Concentrations of total plasma homocysteine, vitamin $\mathrm{B}_{6}$ and serum folate and vitamin $\mathrm{B}_{12}$ were measured by conventional methods. Genomic DNA methylation was measured by a new liquid chromatography/MS method and promoter methylation status of the oestrogen receptor $(E R) \alpha, E R \beta$ and $p 16$ genes was analysed by methylation-specific PCR after bisulfite treatment. The CEE phase demonstrated a significantly decreased mean of total plasma homocysteine concentrations compared with the placebo phase $(8.08 \mu \mathrm{mol} / 1(6.82-9.39)$ v. 9.29 $(7.53-11.35), P<0.05)$ but there was no difference in the blood concentrations of the three B vitamins. The CEE phase also showed a significantly increased genomic DNA methylation in peripheral mononuclear cells compared with the placebo phase (2.85 (SD 0.12) ng methylcytosine/ $\mu \mathrm{g}$ DNA $v$. 2.40 \pm (SD 0.15) $P<0 \cdot 05$ ). However, there was no difference in promoter methylation in the $E R \alpha, E R \beta$ and $p 16$ genes. This study demonstrates that decreased homocysteinaemia by CEE therapy parallels with increased genomic DNA methylation, suggesting a potential new candidate mechanism by which ERT affects the risk of cancers and a possible new candidate biomarker for the oestrogen-related carcinogenesis through folate-related one-carbon metabolism.
\end{abstract}

Oestrogen replacement therapy: DNA methylation: Homocysteine: Cancer risk: Folate: Vitamin $\mathbf{B}_{12}$ : Vitamin $\mathbf{B}_{6}$

Oestrogen hormones have been regarded as major players in carcinogenesis and, particularly, oestrogen replacement therapy (ERT) has been considered to affect, through various mechanisms, the risk of cancers originated from breast, ovary, endometrium and colon (Beral et al. 2002). To date, however, the precise mechanism(s) by which oestrogen affects carcinogenesis remains unclear.

The Third National Health and Nutrition Examination Survey (Morris et al. 2000) suggested that higher oestrogen status is associated with decreased serum total homocysteine (tHcy) concentration and a series of trials evaluating the effect of oestrogen have subsequently demonstrated that oestrogen can reduce tHcy in postmenopausal women (Tutuncu et al. 2005). Since $\mathrm{Wu} \& \mathrm{Wu}$ (2002) proposed that elevated tHcy can be a risk factor for cancer as well as an important tumour marker, it is, however, not clear what role the oestrogen-related decrease in tHcy plays in the risk of disease.

DNA methylation is a major epigenetic mechanism of DNA known to be modulated by nutrients involved in the folatemediated pathway (Choi \& Friso, 2006; Ulrich, 2006). Therefore, we ought to investigate a potential mechanism by which oestrogen may reduce tHcy, in view of the evidence that this lowering effect on tHcy is similar to that observed by supplementation with folic acid and/or other B-vitamins, which are regarded as putative chemopreventive agents (Kim, 2003; Biasco \& Di Marco, 2005; Kane, 2005). We also investigated the subsequent molecular effects of reduced tHcy induced by ERT, considering that a reduction of tHcy affects DNA methylation, which is a well-described mechanism for carcinogenesis, and tHcy concentration reflects the coordinate regulation of one-carbon metabolism (Selhub \& Miller, 1992),

\footnotetext{
Abbreviations: CEE, conjugated equine oestrogen; ER, oestrogen receptor; ERT, oestrogen replacement therapy; SAdoHcy, S-adenosylhomocysteine; THcy, total homocysteine.

* Corresponding author: Dr Simonetta Friso, fax +39045 580111, email simonetta.friso@univr.it
} 
which has two critical pathways for carcinogenesis, DNA methylation and nucleotide synthesis (Choi \& Mason, 2000).

In the present study we evaluate the effect of ERT on onecarbon metabolism biomarkers, including DNA methylation, in order to establish a potential candidate mechanism by which ERT exerts its role in carcinogenesis.

\section{Experimental methods}

\section{Study subjects}

The study protocol was approved by the Institutional Review Board of Tufts-New England Medical Center, Boston, MA, USA. Study candidates provided written informed consent and underwent a screening visit consisting of an interview including past and present medical history, physical examination, registration of vital signs, electrocardiogram and laboratory tests. Postmenopausal status was determined as absence of menstrual periods for more than 1 year. Exclusion criteria were a positive history of CHD and/or thromboembolism, liver or kidney disease, diabetes mellitus, thyroid dysfunction, history of cancer of the breast, uterus or cervix. In addition, women who smoked or drank more than two alcoholic drinks per week were excluded from the study. Subjects were also instructed to stop their daily regimen of multivitamins and nutritional supplements, where applicable. Women who had previously been on an ERT regimen were asked to stop their treatment for at least 3 months before entering into the study.

The present study was designed as a placebo-controlled, double-blind, randomized, cross-over study consisting of two different phases, placebo and conjugated equine oestrogen (CEE; 0.625 mg/d; Lamon-Fava et al. 2003). Oestrogen replacement was provided as oral tablets containing $0.625 \mathrm{mg} \mathrm{CEE}$ while placebo consisted of a tablet identical to the active $\mathrm{CEE}$ tablet, but without the active compound. The study compliance was assessed by tablet counting at the end of each phase: greater than $80 \%$ compliance was observed in all subjects.

Thirteen healthy postmenopausal women (age 57((SD 6) years; weight 69.9 (SD 12.3 kg)) were enrolled into the study.

Each phase lasted 8 weeks and phases were separated by at least a 4-week wash-out period, which was defined by previous studies as an appropriate time frame for the disappearance of oestrogen-induced biological effects (Koh et al. 1997). At week 8 of each phase, blood was drawn after a 12-h fast to measure plasma tHcy, plasma pyridoxal-5'-phosphate (the active form of vitamin $\mathrm{B}_{6}$ ), serum folate and vitamin $B_{12}$ concentrations. DNA was extracted from peripheral blood mononuclear cells to measure genomic and promoter DNA methylation.

\section{Biochemical analyses}

Total plasma homocysteine was determined by HPLC with a fluorometric detection method (Vester \& Rasmussen, 1991). Plasma vitamin $\mathrm{B}_{6}$ (as its active form pyridoxal $5^{\prime}$-phosphate) was determined enzymatically using tyrosine decarboxylase (Camp et al. 1983). Serum folate and vitamin $\mathrm{B}_{12}$ concentrations were determined by a radioassay method using a commercially available kit (Quantaphase II B12/folate radioassay; Bio-Rad, Hercules, CA, USA).

\section{Genomic DNA methylation measurement}

Genomic DNA methylation was determined by liquid chromatography/MS (Friso et al. 2002).

Briefly, $1 \mu \mathrm{g}$ DNA was hydrolysed by sequential digestion with three enzymes, nuclease P1 (Fisher Scientific, Pittsburgh, PA, USA), phosphodiesterase I (Sigma, St Louis, MO, USA) and alkaline phosphatase (Sigma). The hydrolysed DNA solution was delivered onto the analytical column (Supelco, Bellefonte, PA, USA) in isocratic mode. Electrospray ionization MS was performed in positive ion mode (Agilent, Billerica, MA, USA). Identification of 5-methylcytosine was obtained by MS analysis of chromatographic peaks. The isotopomer, methyl-D3, ring-6-D1 5-methyl-2'-deoxycytidine (Cambridge Isotope Laboratories, Andover, MA, USA), was used as an internal standard allowing the quantification of absolute amounts of the methylated cytosine residues in genomic DNA (ng 5-methylcytosine/ $\mu$ g DNA).

\section{Promoter DNA methylation measurement}

Promoter DNA methylation of the oestrogen receptor $(E R) \alpha$, $E R \beta$ and p16 genes was analysed by a methylation specificPCR technique as described in previous reports (Sasaki et al. 2002).

\section{Statistical analysis}

The statistical computations were performed with SPSS statistical software package version 13.0 (SPSS Inc, Chicago, IL, USA). Distribution of variables was assessed for normality. Distributions of continuous variables such as DNA methylation data were expressed as mean values and standard deviations. Logarithmic transformation was performed on all the skewed variables to normalize their distribution. Therefore, geometric means (antilogarithms of the transformed means) are presented for tHcy, folate, vitamin $B_{6}$ and vitamin $B_{12}$. All variables were compared between CEE and placebo phases by Student's paired samples $t$ test. All $P$ values were two-tailed, and values of $P<0.05$ were considered to indicate statistical significance. All CI were calculated at the $95 \%$ level.

\section{Results}

Plasma tHcy concentrations were significantly decreased during the CEE phase compared with the placebo phase $(P=0 \cdot 032$, by paired samples Student's $t$ test) (Table 1$)$. Mean thcy concentration during the placebo phase, 9.29 (7.53-11.35) $\mu \mathrm{mol} / \mathrm{l}$, was within the range considered as normal (Stabler \& Allen, 2004) and the CEE treatment reduced the value of tHcy to 8.08 (6.82-9.39) $\mu \mathrm{mol} / \mathrm{l}$. A significantly increased level of genomic DNA methylation in peripheral mononuclear cells was observed after the CEE phase compared with the placebo phase (2.85 (SD 0.12) ng methylcytosine/ $\mu$ g DNA v. $2 \cdot 40$ (SD $0 \cdot 15), P=0.042$, by paired samples Student's $t$ test) (Fig. 1).

In spite of changes in genomic DNA methylation, there was no significant difference in the promoter DNA methylation of 
Table 1. Biochemical characteristics of the study group at the end of the placebo and oestrogen replacement therapy phases

(Mean values and $95 \% \mathrm{Cl}$ )

\begin{tabular}{|c|c|c|c|c|c|}
\hline & \multicolumn{2}{|c|}{ Placebo } & \multicolumn{2}{|c|}{ CEE } & \multirow[b]{2}{*}{$P$ value } \\
\hline & Mean & $95 \% \mathrm{Cl}$ & Mean & $95 \% \mathrm{Cl}$ & \\
\hline S-folate $(\mathrm{nmol} / \mathrm{l})$ & $10 \cdot 80$ & $8 \cdot 75,13 \cdot 19$ & $11 \cdot 82$ & $9 \cdot 67,14.43$ & NS \\
\hline S-vitamin $\mathrm{B}_{12}(\mathrm{pmol} / \mathrm{l})$ & 420 & 376,473 & 395 & 320,488 & NS \\
\hline P-vitamin $\mathrm{B}_{6}(\mathrm{nmol} / \mathrm{l})$ & 54.05 & $36.96,79.04$ & 48.42 & $32.78,71.52$ & NS \\
\hline P-tHcy $(\mu \mathrm{mol} / \mathrm{l})$ & 9.29 & $7.53,11.35$ & 8.08 & $6.82,9.39$ & 0.032 \\
\hline
\end{tabular}

Statistical difference was evaluated by paired samples Student's $t$ test $(n 13)$. Serum folate and vitamin $\mathrm{B}_{12}$ and plasma vitamin $\mathrm{B}_{6}$ and thcy data are presented as geometric means (antilogarithms of the transformed means) and $95 \% \mathrm{Cl}$ are reported with two-tailed $P$ values. CEE, conjugated equine oestrogen. For details of subjects and procedures, see p. 618

the $E R \alpha, E R \beta$ and $p 16$ genes between the CEE and placebo phases. Serum folic acid, vitamin $\mathrm{B}_{12}$ and plasma vitamin $\mathrm{B}_{6}$ concentrations (Table 1) also showed no significant difference between the two phases.

\section{Discussion}

ERT has been observed to be associated with the risk of major cancers (Beral et al. 2002). However, past studies have not been able to explain the mechanism(s) that can support such association. Interestingly, most, but not all (Farag et al. 2003) studies have demonstrated that ERT reduces plasma tHcy concentrations (Tutuncu et al. 2005). Since Bvitamin status is a major determinant of plasma tHcy, whose levels reflect those of intracellular S-adenosylhomocysteine (SAdoHcy), a compound that can affect cellular DNA methylation (Yi et al. 2000), we investigated whether the homocysteine-reducing effect of ERT is related to B-vitamin status and whether reduced tHcy levels induced

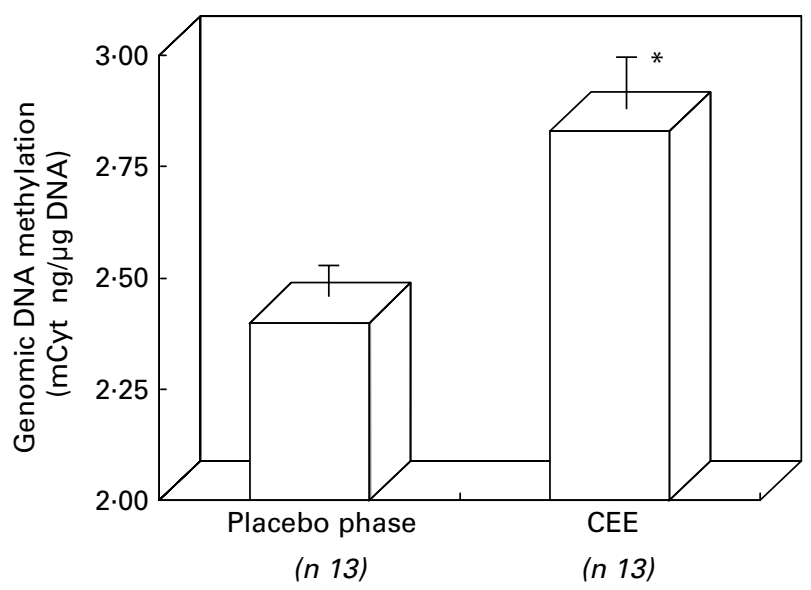

Fig. 1. Effects of oestrogen replacement therapy on genomic DNA methylation. A significant difference in genomic DNA methylation of peripheral mononuclear cells is observed between the placebo and conjugated equine oestrogen (CEE) phases; ${ }^{*} P=0.042$. Genomic DNA methylation is represented by an absolute amount of 5-methylcytosine (mCyt) in genomic DNA (ng $\mathrm{mCyt} / \mu \mathrm{g}$ DNA). Values are expressed as means and standard deviations. Statistical difference was evaluated by Student's paired samples $t$ test. For details of subjects and procedures, see p. 618 . by ERT affect DNA methylation status, either genomic or gene-specific, both of which are well-described mechanisms for carcinogenesis.

The remethylation pathway in one-carbon metabolism converts homocysteine to methionine using a folate- and vitamin $\mathrm{B}_{12^{-}}$dependent methionine synthase reaction (Selhub \& Miller, 1992). The transsulfuration pathway also condenses homocysteine with serine to form cystathionine in an irreversible reaction catalysed by the vitamin $\mathrm{B}_{6}$-dependent cystathionine- $\beta$-synthase reaction. Thus, these three B-vitamins are major determinants of the two main pathways of homocysteine metabolism. In a randomized, double-blind, placebocontrolled study, a 3-month treatment with oestrogen decreased fasting tHcy, accompanied by a decrease in plasma vitamin $\mathrm{B}_{6}$ but not folate and vitamin $\mathrm{B}_{12}$ (Smolders et al. 2005). In another randomized placebo-controlled trial, 12-weeks of ERT also induced a $25 \%$ decrease in plasma vitamin $B_{6}$ but no changes in serum folate and vitamin $B_{12}$ concentrations (Smolders et al. 2004). In the latter study, fasting tHcy concentration was decreased by $12 \%$ but, interestingly, post-methionine loading tHcy concentration was significantly increased (Smolders et al. 2004). Compared with these two studies, we found a significant decrease in tHcy concentrations and non-significant changes in vitamin $\mathrm{B}_{6}$ during the ERT phase, as compared with the placebo phase. It is possible that a treatment period of 8 weeks, such as that of the present study, is not sufficient to induce vitamin $\mathrm{B}_{6}$ depletion as compared with the 3-months length of the previous studies (Smolders et al. 2004, 2005). Dimitrova et al. (2002), furthermore, reported that oestrogen increases plasma concentration of glutathione, an end-product of the transsulfuration pathway, by enhancing cysthationine $\beta$ synthase activity.

Collectively, from these observations we can speculate that oestrogen enhances the transsulfuration pathway, which needs vitamin $B_{6}$ as a cofactor. Sustained increase of this pathway activity by ERT might induce vitamin $\mathrm{B}_{6}$ depletion, which can cause a positive post-methionine loading test. In 1962 , Finkelstein reported that treatment with oestradiol significantly increased the activities of methionine-activating enzymes (Finkelstein, 1962), suggesting an effect of oestrogen on the remethylation pathway. In the present study, however, no changes in serum folate and vitamin $B_{12}$ were observed, consistent with other previous studies (Smolders et al. 2004, 2005). 
The regenerated methionine from homocysteine converts to S-adenosylmethionine, which transfers its methyl group to the $5^{\prime}$ position of cytosine for DNA methylation reaction and is converted to SAdoHcy.

DNA methyltransferases bind SAdoHcy with higher affinity than S-adenosylmethionine and they are, therefore, subject to potent product inhibition by SAdoHcy. Under normal conditions, SAdoHcy is hydrolysed by SAdoHcy hydrolase to adenosine and homocysteine. However, this reaction is readily reversible with equilibrium dynamics that favour SAdoHcy synthesis rather than its hydrolysis. Thus, a chronic elevation in plasma homocysteine levels usually has an indirect and negative effect on cellular methylation reactions through a concomitant increase in intracellular SAdoHcy levels (Yi et al. 2000). Therefore, we hypothesize that a decreased plasma tHcy concentration induced by oestrogen therapy may diminish, indirectly, the intracellular SAdoHcy concentrations, thereby reducing the inhibitory effect of SAdoHcy on DNA methylation and increasing cellular genomic DNA methylation. To the best of our knowledge, this is the first observation demonstrating that decreased tHcy by ERT increases genomic DNA methylation.

DNA methylation, more specifically the transfer of a methyl group at the carbon- $5^{\prime}$ position of cytosine at $5^{\prime}-\mathrm{CpG}-3^{\prime}$ dinucleotides residues, is an epigenetic phenomenon, which is involved in gene expression and genome integrity. While methylation within gene regulatory elements, such as promoters, generally suppresses the gene function, methylation within gene-deficient regions such as pericentromeric heterochromatin maintains the conformation and integrity of the chromosome. Thus, the evaluation of DNA methylation status is important for the study of carcinogenesis (Friso \& Choi, 2002). A decreased level of genomic DNA methylation is a nearly universal finding in tumorigenesis and appears early in carcinogenesis and generally precedes the mutation and deletion events that occur later in the evolution of cancer (Goelz et al. 1985). Although rodent studies have suggested that genomic DNA hypomethylation by itself can induce cancer (Gaudet et al. 2003), we do not know whether the mechanism that mediates the ERT-related increases in genomic DNA methylation in peripheral mononuclear cells is related to reduced risk of colon cancer or enhanced risk of breast cancer. Since the effect of tHcy on DNA methylation is highly tissue-specific (Choumenkovitch et al. 2002), we also cannot entirely explicate whether our observation is specific for peripheral mononuclear cells. Nevertheless, the observation that ERT alters genomic DNA methylation status is very meaningful because it suggests a candidate mechanism as well as a new biomarker for the study of oestrogen-related carcinogenesis.

In both reproductive and non-reproductive tissues, oestrogen regulates cell growth and differentiation through ER, which have a critical role in breast and colorectal carcinogenesis (Fiorelli et al. 1999). There are two types of $E R, \alpha$ and $\beta$, which show differential expression in various tissues. Studies have suggested that the chemopreventive effect of ERT in colonic carcinogenesis is associated with an increase in $E R \beta$ and a decrease in $E R \alpha$ expression (Weyant et al. 2001). Issa et al. (1994) reported that one of the earliest events that predisposes to sporadic colorectal carcinogenesis is the inactivation of $E R$ genes by promoter methylation. Other cancers originated from breast, endometrium and prostate also showed a relationship between the promoter methylation and loss of expression in ER genes (Sasaki et al. 2002). We, therefore, evaluated the promoter methylation status of $E R \alpha$ and $E R \beta$ along with $p 16$, a tumour suppressor gene frequently found to be hypermethylated in those cancers, but no significant difference between the two phases was observed. This negative observation suggests that: 1) in contrast to genomic DNA hypomethylation, which can induce a compensatory promoter hypermethylation, increased genomic DNA methylation by ERT might not necessarily affect promoter methylation; 2) 8-week treatment with ERT in the present study might not be long enough to change the promoter methylation; 3) significant changes in promoter methylation of these genes might be hardly found before cancer conversion; 4) response of promoter methylation also might be tissue-specific.

One limitation of the study is the restricted number of subjects and some of the endpoints, such as plasma vitamin $\mathrm{B}_{6}$ concentrations, likely due to this reason could not show statistically significant differences between the placebo and ERT groups.

Yet in the present study, ERT indeed reduced tHcy concentration in plasma with a concurrent increase in DNA methylation. Since DNA methylation is critical to carcinogenesis, the altered DNA methylation may be a mechanism by which ERT modulates the risk of cancer. The present study also suggests that DNA methylation can be a good biomarker for the study of oestrogen-related carcinogenesis.

\section{Acknowledgements}

This work has been supported by grants from the Regione Veneto, the Cariverona Foundation (S.F.) and the National Institutes of Health Clinical Investigator Development Award HL 03209 (S.L-F.), and the National Institute of Health Grants R21AA016681-01 (S-W.C). Any opinions, findings, conclusion or recommendations expressed in this publication are those of the author(s) and do not necessarily reflect the view of the U.S. Dept of Agriculture.

\section{References}

Beral V, Banks E \& Reeves G (2002) Evidence from randomised trials on the long-term effects of hormone replacement therapy. Lancet 360, 942-944.

Biasco G \& Di Marco MC (2005) Folate and prevention of colorectal cancer in ulcerative colitis. Eur J Cancer Prev 14, 395-398.

Camp VM, Chipponi J \& Faraj BA (1983) Radioenzymatic assay for direct measurement of plasma pyridoxal 5'-phosphate. Clin Chem 29, 642-644.

Choi SW \& Friso S (2006) Interaction between folate and methylenetetrahydrofolate reductase gene in cancer. In Nutrient-gene Interactions in Cancer, pp. 57-74 [S Friso and S-W Choi, editors]. Boca Raton, FL: CRC Press.

Choi SW \& Mason JB (2000) Folate and carcinogenesis: an integrated scheme. J Nutr 130, 129-132.

Choumenkovitch SF, Selhub J, Bagley PJ, Maeda N, Nadeau MR, Smith DE \& Choi SW (2002) In the cystathionine beta-synthase knockout mouse, elevations in total plasma homocysteine increase tissue S-adenosylhomocysteine, but responses of S-adenosylmethionine and DNA methylation are tissue specific. J Nutr 132, 2157-2160.

Dimitrova KR, DeGroot K, Myers AK \& Kim YD (2002) Estrogen and homocysteine. Cardiovasc Res 53, 577-588. 
Farag NH, Barshop BA \& Mills PJ (2003) Effects of estrogen and psychological stress on plasma homocysteine levels. Fertil Steril 79, 256-260.

Finkelstein JD (1962) Methionine metabolism in mammals: effects of age, diet, and hormones on three enzymes of the pathway in rat tissues. Arch Biochem Biophys 122, 583-590.

Fiorelli G, Picariello L, Martineti V, Tonelli F \& Brandi ML (1999) Functional estrogen receptor beta in colon cancer cells. Biochem Biophys Res Comm 261, 521-527.

Friso S \& Choi SW (2002) Gene-nutrient interactions and DNA methylation. J Nutr 132, Suppl., 8, 2382S-2387S.

Friso S, Choi SW, Dolnikowski GG \& Selhub J (2002) A method to assess genomic DNA methylation using high-performance liquid chromatography/electrospray ionization mass spectrometry. Anal Chem 74, 4526-4531.

Gaudet F, Hodgson JG, Eden A, Jackson-Grusby L, Dausman J, Gray JW, Leonhardt H \& Joenisch R (2003) Induction of tumors in mice by genomic hypomethylation. Science 300, 489-492.

Goelz SE, Vogelstein B, Hamilton SR \& Feinberg AP (1985) Hypomethylation of DNA from benign and malignant human colon neoplasms. Science 228, 187-190.

Issa JP, Ottaviano YL, Celano P, Hamilton SR, Davidson NE \& Baylin SB (1994) Methylation of the oestrogen receptor CpG island links ageing and neoplasia in human colon. Nat Genet $\mathbf{7}$, $536-540$

Kane MA (2005) The role of folates in squamous cell carcinoma of the head and neck. Cancer Detect Prev 29, 46-53.

Kim YI (2003) Role of folate in colon cancer development and progression. J Nutr 133, 3731S-3739S.

Koh KK, Mincemoyer R, Bui MN, Csako G, Pucino F, Guetta V, Waclawiw M \& Cannon RO 3rd (1997) Effects of hormonereplacement therapy on fibrinolysis in postmenopausal women. $N$ Engl J Med 336, 683-690.

Lamon-Fava S, Posfai B \& Schaefer EJ (2003) Effect of hormonal replacement therapy on C-reactive protein and celladhesion molecules in postmenopausal women. Am J Cardiol 91, 252-254.

Morris MS, Jacques PF, Selhub J \& Rosenberg IH (2000) Total homocysteine and estrogen status indicators in the Third National Health and Nutrition Examination Survey. Am J Epidemiol 152, $140-148$.

Sasaki M, Tanaka Y, Perinchery G, Dharia A, Kotcherguina I, Fujimoto S \& Dahiya R (2002) Methylation and inactivation of estrogen, progesterone, and androgen receptors in prostate cancer. J Natl Cancer Inst 94, 384-390.

Selhub J \& Miller JW (1992) The pathogenesis of homocysteinemia: interruption of the coordinate regulation by S-adenosylmethionine of the remethylation and transsulfuration of homocysteine. Am J Clin Nutr 55, 131-138.

Smolders RG, de Meer K, Kenemans P, Jakobs C, Kulik W \& van der Mooren MJ (2005) Oral estradiol decreases plasma homocysteine, vitamin B6, and albumin in postmenopausal women but does not change the whole-body homocysteine remethylation and transmethylation flux. J Clin Endocrinol Metab 90, 2218-2224.

Smolders RG, de Meer K, Kenemans P, Teerlink T, Jakobs C \& van der Mooren MJ (2004) Hormone replacement influences homocysteine levels in the methionine-loading test: a randomized placebo controlled trial in postmenopausal women. Eur J Obstet Gynecol Reprod Biol 117, 55-59.

Stabler SP \& Allen RH (2004) Megaloblastic anemias. In Textbook of Medicine, 22nd ed. pp. , 1050-1057 [L Goldman and D Ausiello, editors]. Philadelphia: Saunders.

Tutuncu L, Ergur AR, Mungen E, Gun I, Ertekin A \& Yergok YZ (2005) The effect of hormone therapy on plasma homocysteine levels: a randomized clinical trial. Menopause 12, 216-222.

Ulrich C (2006) Genetic variability in folate-mediated one-carbon metabolism and cancer risk. In Nutrient-Gene Interactions in Cancer, pp. 75-91 [S Friso and S-W Choi, editors]. Boca Raton, FL: CRC Press.

Vester B \& Rasmussen K (1991) High performance liquid chromatography method for rapid and accurate determination of homocysteine in plasma and serum. Eur J Clin Chem Clin Biochem 29, $549-554$

Weyant MJ, Carothers AM, Mahmoud NN, Bradlow HL, Remotti H, Bilinski RT \& Bertagnolli MM (2001) Reciprocal expression of ERalpha and ERbeta is associated with estrogen-mediated modulation of intestinal tumorigenesis. Cancer Res 61, 2547-2551.

Wu LL \& Wu JT (2002) Hyperhomocysteinemia is a risk factor for cancer and a new potential tumor marker. Clin Chim Acta 322, $21-28$.

Yi P, Melnyk S, Pogribna M, Pogribny IP, Hine RJ \& James SJ (2000) Increase in plasma homocysteine associated with parallel increases in plasma S-adenosylhomocysteine and lymphocyte DNA hypomethylation. $J$ Biol Chem 275, $29318-29323$ 